\title{
Not your problem? Exploring the relationship between problem formulation and social responsibility
}

\section{Sveinung Jorgensen and Lars Jacob Tynes Pedersen}

This article explores the relationship between organizational problem formulation and social responsibility. The purpose of the article is to illuminate how organizational problem formulations (1) determine the manner in which the organization attempts to solve the problem and (2) involve the ascription of significance to a group of stakeholders seen as relevant for the organization. This has implications for the degree to which they assume responsibility for those stakeholders. We discuss three dimensions of responsible decision making - rationality in goal attainment, reverence for ethical norms, and respect for stakeholders. Thereby, we arrive at an understanding of how different organizations in the same sector conceive of, and attempt to solve fundamental problems in the sector, as well as how their assumed responsibility is reflected therein. We present and discuss a case that discusses key similarities and differences between two organizations in the drug sector - a pharmaceutical company that produces medicine for the treatment of drug addiction and a foundation working with drug rehabilitation. We illuminate how the two organizations base their activities on divergent formulations of the drug problem and how this is manifested in their approach to the problem. We argue that
Sveinung Jorgensen Faculty of Economics and Organisational Science, Lillehammer University College sveinung.jorgensen@ hil.no

Lars Jacob Tynes Pedersen

Department of Accounting, Auditing and Law, Norwegian School of Economics and Business Administration lars.pedersen@nhh.no 
this ultimately translates into differences in the inclusion of various stakeholders in their problem space, and thereby the degree to which they assume responsibility for key stakeholders. This contributes to the corporate social responsibility literature by providing an in depth account of how problem formulations shape organizational activities and determine the practical inclusion of stakeholders' interests in the decisions and activities of organizations.

Keywords: corporate social responsibility, decision making, problem formulation, stakeholder management

\section{Introduction}

A fundamental question in the corporate social responsibility (CSR) literature is how and why organizations differ in the degree to which they assume responsibility for the different stakeholders who are affected by their activities. This article investigates the relationship between organizational activities and social responsibility by illuminating how the interests of stakeholders are taken into account in the crucial task of formulating the basic problems that the organization is faced with (see e.g. Eierman \& Philip 2003; Lyles \& Mitroff 1980).

The purpose of this article is to illuminate how organizational problem formulations (1) determine the manner in which the organization attempts to solve the problem and (2) involve the ascription of significance to the interests of a group of stakeholders seen as relevant for the organization. This has implications for the degree to which the organizations assume responsibility for those stakeholders and can be seen both as an expression of the organization's values and as a strategic adaptation due to the perception of the stakeholders as potentially powerful (see, e.g., Mitchell, Agle \& Wood 1997). We propose a problem formulation framework, whereby we illuminate the relationship between problem formulation and responsibility for stakeholders. This frames our investigation of how organizations' divergent conceptions of values at stake in problems lead them to (1) emphasize different features of the given problem in their problem formulations and (2) pursue different solutions to the problem, with different consequences for important stakeholders (cf. Mitroff \& Silvers 2009; Jørgensen \& Pedersen 2010).

Hence, the main thesis of this article can be summarized as follows. The problem formulation taken up by an organization frames the problem space (or decision space) of that organization. This involves determining (1) the goals of the organization, (2) the norms that constrain goal attainment, and (3) the inclusion of stakeholders in the problem space (cf. Zsolnai 2009). Therefore, the problem formulation taken up by the organization has impli- 
cations for the degree to which the organization's activities take into account its responsibility for important stakeholders. In order to explore our main thesis, we present and discuss a case from the drug sector. The case illustrates how two rival problem formulations of the same issue (i.e. the drug problem) coexist in the same sector. We explore key similarities and differences between the two organizations' formulations of the drug problem, as well as about how they aim to solve the problem based on their conception of it. The rival formulations represented by the two organizations reflect a conflictive understanding of the drug problem that is salient in the sector. We argue that the divergence involves a difference in the degree to which they balance the different values at stake for different stakeholders in their problem formulations (cf. Jørgensen \& Pedersen 2010; Ims \& Zsolnai 2009). Hence, it deals with the inclusion of stakeholder interests in practical decision making, and thereby with the social responsibility of the two organizations taken up for the case study. The article contributes to the CSR literature by illuminating how organizational problem formulations are important for the organization's ability to identify relevant stakeholders and take their interests into account. We explore this relationship in a real life case of a complex, social issue.

The article is structured as follows. First, we outline our problem formulation framework and illuminate how the values at stake for stakeholders are reflected therein. Second, we present the case and highlight how it represents divergent problem formulations of the drug problem. Third, we discuss the case in light of our theoretical framework. Finally, we synthesize the findings and outline implications.

\section{Theoretical framework}

In this section, we outline our theoretical framework. First, we present our problem formulation framework, wherein we also explore how values are reflected in problem formulations. Second, we illuminate how this relates to the organizations' social responsibility by exploring stakeholder inclusion in problem formulation.

\section{Problem formulation and values}

Management theory and practice are preoccupied with solutions. Organizations are problem solving systems (Blau \& Scott 1962), and the choices, decisions and actions made by organizations and the individuals therein ultimately relate to an attempt at solving the problems that the organizations are faced with. However, we argue that to arrive at adequate solutions to a given problem, problems need to be properly formulated. Problem for- 
mulation includes defining the gap between the current state and the desired state, as well as searching for and identifying the causes of the discrepancy (Eierman \& Philip 2003: 354). In the face of any problem, there are several ways in which the problem can be formulated. The objective of problem formulation is to develop an appropriate formulation. Hence, we may envision that several competing problem formulations adequately equip the problem solver with an understanding of the nature of the problem, and how it represents the divergence between the present state and the desired state.

Mitroff (1998: 18) asserted that «[h]ow we initially formulate or define a problem, the actions we take, and the arguments we use to justify those actions are all inextricably intertwined.» Hence, an organization's solution to a problem that it faces follows from the way in which it initially formulates the problem, since the problem formulation determines the boundaries within which the search for feasible solutions is conducted, viz. the solution space (Büyükdamgaci 2003). Moreover, the formulation reflects the organization's actual values, since any choice is based on the prioritization of something over something else. Hence, a problem formulation that emphasizes factors $a, b$, and $c$ rather than factors $d, e$, and $f$ already involves a value judgment of the relative importance of some factors over others in approaching the problem. As such, problem formulation involves judging relevance, assigning value and justifying prioritizations, which reflect underlying values (cf. Vetlesen \& Henriksen 2003).

As argued by Vickers (1965), problem formulation involves making judgments about reality, i.e., what are matters of fact and value judgments with regard to the facts' significance. Hence, values are important for problem formulation because they determine which factors are important enough to be taken into consideration when approaching and formulating a problem, and the relative importance that is ascribed to each of these factors when determining the boundaries of the problem. ${ }^{1}$ Moreover, values are central to problem formulation since different problem formulations of the same basic problem may differently reflect the values at stake in the situation, and thus differ in their ability to render the problem solver capable of conceiving of the ethically relevant factors of the problem. Hence, an appropriate problem formulation implicitly or explicitly reflects (1) relevant stakeholders of the problem, (2) the values at stake in the situation, and thereby providing a basis for evaluation and (3) how different outcomes have different value implications for the various stakeholders (Pedersen 2009).

In two different ways, then, the actual values of the organizations are reflected in the manner in which they approach their problems. First, organizational problem formulations reflect the organization's conception of which values are at stake and for whom, as well as the organization's identification and inclusion of stakeholders in the problem space. Second, the 
organization's preferred solutions to those problems which are largely framed by the manner in which the problem is formulated - reveal the value and interest prioritizations of the organization. In practice, CSR involves giving priority to organizational stakeholders at the (potential) expense of the organization itself, which indicates the relationship between problem formulation and responsibility. In the following section, we explore this relationship further.

\section{Problem formulation, stakeholder inclusion, and social responsibility}

We highlighted that defining the gap between the desired and the present state is central to problem formulation. This relates closely to what the goals of the organization are, since the organization's desire is reflected in its goals. In organizational life, Zsolnai (2009) notes, an organization's goals cannot be seen as independent of the interests of its stakeholders, since those interests are affected - negatively or positively - through the attempted goal attainment of the organization. Zsolnai further postulates a three-component model of responsible decision making, wherein he distinguishes between (1) rationality in goal attainment, i.e., attempting to achieve the organization's goals by using the most efficient means, (2) reverence for ethical norms, i.e., attempting not to transgress the salient norms that relate to the activity in question, and (3) respect for stakeholders, i.e., attempting to take into account the interests of the parties that are influenced by the organization's activities. Hence, in practical decision making, organizations make trade-offs along three dimensions that are rarely in harmony. Zsolnai further formalized his decision making model in mathematical terms, thus making it possible to make a multidimensional evaluation of any decision alternative based on the following vector:

$$
\underline{\mathrm{v}}=[\mathrm{D}(\mathrm{Ai}), \mathrm{G}(\mathrm{Ai}), \mathrm{S}(\mathrm{Ai})]
$$

Here, $\mathrm{D}(\mathrm{Ai})$ represents the deontological value (i.e. the degree to which the decision complies with relevant norms) for any decision alternative A. Similarly, G(Ai) represents the goal attainment value and $\mathrm{S}(\mathrm{Ai})$ represents the stakeholder value, i.e., the degree to which the decision respects the interests of the affected stakeholders. From the perspective of problem formulation, then, the degree to which organizations are able to make socially responsible decisions is a function of the degree to which their goal (i.e. their desired state) does not (1) involve the transgression of important ethical norms or (2) unreasonably influence stakeholders in a negative way.

This implies that the relationship between problem formulation and social responsibility can be understood with reference to the degree to 
which problem formulations imply the inclusion of the interests of a broad or narrow set of stakeholders. Hence, the value judgments that are implicit in problem formulations (cf. Vickers 1965) determine both which stakeholders are taken into account and which norms are seen as relevant constraints on decisions and behavior. To explore the responsibility implied by organizational problem formulations, we need to investigate rival problem formulations with regard to the three elements outlined above. We pursue this in the following pages.

\section{Method}

In this section, we outline our methodological choices. First, we present the rationale for, and the design of, our case study. Second, we briefly justify the selection of the case. Finally, we discuss data collection procedures.

In order to investigate the relationship between problem formulation and social responsibility empirically, we conducted a theory-driven case study. This is appropriate for the present study for three reasons. First, the case study is fitting for understanding complex social phenomena, while retaining the holistic characteristics of the phenomenon under investigation (Yin 2001). As asserted by Yin (2001: 9), case studies are suitable when the research question asks 'how' - in our case how organizational problem formulations indicate the organization's horizon of responsibility. Second, case studies are appropriate when one has well-grounded theoretical insight into a phenomenon and aims to improve on this insight with respect to particular features. By employing and combining the theories on problem formulation and responsible decision making, we aim to fill the gap in theory in the intersection between the two. Finally, the method allows for a justifiable development of theoretically grounded criteria for data collection and analysis (Yin 2001).

We conducted an embedded, single-case study (Yin 2001). Hence, the objective was to search for cross-case patterns of similarities and differences (Eisenhardt 1989: 540). In order to maximize the utility of information from the small samples, we employed information-oriented sampling - specifically, paradigmatic case sampling (Flyvbjerg 2006). We argue that the case is a paradigmatic case, which in a business context implies that it represents models «stimulating [the] rethinking of business principles and presuppositions» (Ims \& Jakobsen 2006: 24). Hence, by investigating the case, we reveal the differences between rival problem formulations and how they imply differing degrees of responsibility for stakeholders.

We present and analyze a case relating to the societal problem of drug abuse, where we explore the difference between two organizations that both - in different ways - deal with providing solutions for the drug problem. 
The case (1) represents a complex, social problem, (2) deals with organizations that diverge in their attempts to approach this problem, and (3) relates to organizational activities that have major consequences for a broad set of stakeholders, and where there are manifold and incommensurable values at stake.

The data were collected as part of a larger case study we conducted on the Norwegian drug reform and its influence on the drug rehabilitation facility, the Tyrili Foundation. ${ }^{2}$ We collected data through participant observation and unstructured, in-depth interviews with management (1 respondent), staff (4 respondents) and drug abusers (4 respondents) at Tyrili. We also collected historical secondary data about Tyrili's activities, and conducted a semi-structured interview with a manager in a Norwegian regional health enterprise. Moreover, we collected manifold publically available data (reports, public statements, and media coverage) about the pharmaceutical company Reckitt Benckiser and of developments in drug rehabilitation in general. We compiled a comprehensive case study protocol and database (cf. Yin 2001). Permission to pursue interviews with drug abusers was granted by the Norwegian Privacy Ombudsman for Research. Particular care was taken in briefing and debriefing this group of informants and their right to withdraw from the project at any point was emphasized.

\section{Case description}

In this section, we outline the case that serves as the basis for our empirical exploration. To illustrate our main thesis, we present two formulations of the drug problem, framed by pharmaceutical companies and rehabilitation facilities - two organizations that operate at different levels and in different ways in the drug sector. While the pharmaceutical companies mainly formulate the problem as a chemical and medical one, (i.e. addiction) the social-pedagogical rehabilitation facilities emphasize the problem's social and existential dimensions (i.e. abuse), in addition to the medical aspects. ${ }^{3}$ Moreover, we highlight how the involved organizations differ in the degree to which they assume responsibility for stakeholders, and how society at large is influenced by the attempted organizational solutions to the drug problem.

The abuse of drugs is an intriguing and complex issue that is dealt with in different ways. The overarching problem of the drug sector can be broadly defined as finding means to rehabilitate drug abusers, or at least help them to get a better life so that they do not harm themselves or other people. The attempted solution to this problem arguably involves complex and multidisciplinary insights, and different types of organizations - rehabilitation facilities, hospitals, pharmaceutical companies, prisons etc. - all take part in 
grappling with drug abuse. Moreover, they each provide services that are not substitutes, but rather complementary problem solving measures. This implies that if a single problem formulation is allowed to dominate other salient formulations of the problem, it may undermine the contributions of the organizations whose problem formulations are displaced.

A prominent actor in the drug sector is the pharmaceutical company Reckitt Benckiser (RB), which is licensed to distribute the prescription drug Suboxone - a narcotic medication intended for the treatment of opioid dependence. According to the company's annual reports, in 2007 and 2009, RB's future profit depends on further deregulation and doctors' acceptance of Suboxone. One of the ways in which RB promotes Suboxone is the web site www.suboxone.com. On the web site, patients, their relatives, and doctors can learn how to conceive of the drug issue as a disease, such as diabetes or high blood pressure, which can consequently be treated by medicine. For instance, they offer a dictionary in which it is argued that traditional concepts such as drug abuser, drug abuse, and drug problem should be avoided and that one should rather use the concepts dependence, addiction, misuse, and patient to underline that the drug issue should be treated as a medical problem, not as a behavioral problem related to choice, habits, or culture. ${ }^{4}$ Furthermore, it is argued that Suboxone can be used in an office-based or polyclinic setting and that it is well suited for take-home use. Thereby, expensive stays at rehabilitation facilities can be avoided. In order to support the patients in their recovery, RB has also made a web-based program called «Here to Help» ${ }^{5}$ where there are videos and stories about patients, who speak about the effectiveness of the Suboxone medicine.

Hence, RB's approach to solving the drug problem is based on medical treatment, but more profoundly it rests on the conception of the drug problem itself as a medical one. By formulating the drug problem in a manner that emphasizes addiction as the primary aspect of the drug problem, it follows naturally that solutions that remove or heal addiction are preferable. Moreover, as a profit-seeking corporation, RB aims to develop, produce, and market a product that enables them to obtain profits. As such, using the goal-attainment logic of Zsolnai (2009), the goal $G$ of RB is to develop and market a medical product that (1) is effective in treating drug addiction and (2) enables RB to obtain profits.

An approach that diverges from the widespread medicalized treatment approach to the drug problem (see e.g. Conrad 2007) is the one taken up by the Tyrili Foundation (Tyrili), which is a part of the cooperative rehabilitation movement that evolved in the 1970s. In these cooperatives, adults and youth lived and worked together, while solidarity and work had a central position in the rehabilitation process. Tyrili was established in 1980 as a socio-pedagogic rehabilitation alternative to the hospital-based treatment facilities. Today, it offers help to about 200 drug abusers yearly at six diffe- 
rent locations. Tyrili's view of human life is expressed in their slogans «All people carry the possibility of change» and «There are no hopeless people, only situations that seem hopeless». Many things have changed in Tyrili during the last 30 years and only a few of the employees live in the different Tyrili facilities. Traditionally, Tyrili has been reluctant to use medication such as Suboxone, but today, medicine is used as part of their rehabilitation program. Still, Tyrili argues that the drug issue is primarily related to choice, habits, and culture and that their rehabilitation efforts are designed accordingly. Furthermore, they claim that time and relationships with other people are more important than medical treatment. This is reflected in their rehabilitation activities.

Hence, Tyrili's approach to solving the drug problem - which is shared by numerous other facilities of which Tyrili serves as a representative case is based on socialization and unlearning of the abuser's (drug)cultural inclinations, as well as a rebuilding of the abuser's self-image. This is based on the conception of the drug problem as a social and existential problem, and while medical treatment may aid the abuser's journey from abuse to full rehabilitation, more profound measures are required. Hence, by formulating the drug problem in a manner that emphasizes the abuser's self-image and embeddedness in society, it follows that solutions that aid the individual's existential and social development are preferable.

Again following Zsolnai (2009), we argue that the goal $G$ of Tyrili is (1) to offer rehabilitation services that meet the requirements that allow them to obtain clients and (2) to rehabilitate those clients by means of sociopedagogical rehabilitation measures that aid the individual's existential and social development. Important stakeholders - $S$ in Zsolnai's framework are the abusers who become pupils at Tyrili. On the flipside, however, there are abusers who do not get the benefit from Tyrili's rehabilitation measures, since total resource allocation to the drug sector implies a scarcity of resources for rehabilitation. To the extent that Tyrili's approach becomes widespread, then, it may imply that fewer abusers in total get access to rehabilitation. Those individuals are consequently also stakeholders. Also, one may argue that society at large is an important stakeholder, since the effectiveness of the medicine ultimately translates into well-functioning or ill-functioning rehabilitation, which has economic and social consequences for societies.

As pointed out by Jørgensen and Pedersen (2010), the Norwegian drug reform has emphasized the medical aspect of the drug problem. This has made the working conditions increasingly difficult for alternative facilities that approach the drug issue in a socio-cultural manner, i.e., emphasizing lengthy rehabilitation efforts based on building relationships, self-confidence, and a sense of purpose. In the discussion below, we will illuminate a global trend, whereby medical corporations have increased their market 
shares and profits at the expense of nonmedical rehabilitation efforts by pursuing marketing strategies that to a large extent displace nonmedicalized approaches to the drug problem. This has resulted in the society adopting the values and problem formulation spelled out by the commercial medical companies. As such, one may argue that one of the stakeholder groups - $S$ in Zsolnai's (2009) framework - are the organizations and entities who suffer from RB's marketing strategy (in this case Tyrili). Other relevant stakeholders for $\mathrm{RB}$ are the abusers, who are users of the medicine they produce, and doctors with whom RB engage to effectively spread their medicine in the sector. Again, society at large is a stakeholder for the same reasons as in the case of Tyrili above.

In the following section, we analyze this case and illuminate how the coexisting problem formulations take into account stakeholders' interests in different ways. Thereby, we aim to discuss the social responsibility of the two different organizations.

\section{General discussion}

In this section, we analyze the case by means of the theoretical framework. In investigating the problem formulations of the organizations, we start with the manifest solutions professed by each of the organizations. Second, we discuss the goals, ethical norms, and stakeholder inclusion implicit in the problem formulations along the lines of Zsolnai's (2009) framework. Thereby, we aim to shed light on the consequences of the two approaches for important stakeholders and analyze in what sense social responsibility is manifested in the two approaches.

In the case description, we shed light on two different approaches to the drug problem and the ways in which they diverge. We now discuss this further by starting with the observable, manifest variables - namely, the solutions with which the organizations aim to deal with the basic problem. By using them as starting points, we aim to offer an explanation of (1) how they are framed by the way in which the organizations formulate the problem, which is at least indirectly observable, and (2) how they reflect the inclusion of stakeholders in the problem space, and thereby represent value prioritizations of those stakeholders' interests in practical decision making. This can only be observed by means of interpreting the choices, decisions and conduct of the organization, as opposed to taking their espoused theories of core values at face value (cf. Argyris \& Schön 1974).

As asserted, the central issue in drug rehabilitation is finding means to rehabilitate drug abusers, or at least help them to get a better life so that they do not harm themselves or others. At first glance, the two organizations in our study may seem incomparable because they differ fundamentally in 
their very nature. However, both organizations aim to contribute to the solving of the drug problem and offer a comprehensive solution to this problem. These solutions are complementary rather than substitutes. Hence, it makes sense to explore key similarities and differences with regard to their conception of, and subsequent attempts to solve the drug problem.

The different approaches of Tyrili and Reckitt Benckiser (RB) can be explained by a multitude of factors. For instance, they differ in their nature as organizations, they have different resources, both financially and nonfinancially, they operate on different stages in the value chain, and they belong to different professional traditions (i.e. the social work and medical traditions, respectively). Yet, we argue that an important means of understanding why and how they approach the problem differently is the different conceptions of the drug problem that are manifested in their problem formulations. At Tyrili, time, community, and relationship are fundamental priorities in rehabilitation. This directly follows from their conception of the drug problem as relating to habits, being part of a culture, and being cut off from society. Tyrili therefore formulates the problem, i.e., the gap between the present and the desired state, in a manner that emphasizes these aspects. Accordingly, lengthy rehabilitation is preferred to polyclinic treatment, socially and existentially relevant measures to rehabilitation are preferred to medication, and a holistic approach to rehabilitation is assumed. Seeing the drug problem as a multidimensional one thus leads Tyrili to pursue solutions that attempt to integrate these various dimensions of the drug problem.

$\mathrm{RB}$, on the other hand, formulates and endeavors to solve the problem solely as a medical one - thus implying that addiction is the problem and the remedy is to cure addiction. Hence, the preferred solution is to produce effective medicine and to facilitate and promote its use in treatment. Therefore, RB has institutionalized a number of measures that aim to disseminate the notion of the drug problem as a medical problem, for instance the drug dictionary that teaches you to describe the drug problem in medical terms, as well as systems for helping doctors to use their medicine and drug abusers to find doctors who can treat them with RB's medicine. As such, RB's formulation of the drug problem is a unidimensional one, in which the medical dimension is primary, and the solution is tailored to solve the medical problem. Moreover, their conception of the drug problem is embedded in an efficiency logic that supports profitability, which implies that they take steps to promote their conception of the problem - and the corresponding solution - at the expense of other approaches. However, there is still an overlap of approaches of the two organizations, since Tyrili indeed employs medicine as a supporting measure in their rehabilitation activities (even though it is not mandatory for abusers to use medicine). 
More profoundly, we argue that we can illuminate the difference between Tyrili and RB by using Zsolnai's (2009) three-dimensional framework for responsible decision making. Thereby, we can discuss differences in goals, reverence for ethical norms, and inclusion of stakeholder interests to evaluate the degree to which the two organizations' approaches can be deemed socially responsible.

As outlined in the case description, the two organization's goals are very different. The difference is mainly twofold. For one thing, RB is a profit-seeking corporation, while Tyrili is a nonprofit-seeking foundation. Moreover, $\mathrm{RB}$ produces medicine while Tyrili offers rehabilitation services. Both of them, however, aim to make their product or service effective and to succeed in their respective markets. Thus, while their goals share certain similarities, they are fundamentally different in important ways. According to Zsolnai's (2009) framework, this furthermore implies that the two organizations will evaluate their action alternatives differently with respect to the goal-attainment value - $G(A i)$ - of those alternatives.

The second element by which we can explore the difference between the two problem formulations and the decisions to which they lead is the exploration of the ethical norms to which the organizations show reverence. As a proxy for this, we shed light on the expressed values of the two organizations, even though we are aware that expressed values may diverge from actual values (cf. Argyris \& Schön 1974; van Rekom 2006). Values can be seen as expressions of both what is desirable and what is worthy of protection, which means that values indicate the moral constraints that organizations place on their activities. While this is not synonymous to ethical values, it is reasonable to expect that expressed values are at least in part influenced by the norms organizations perceive as important in their environments.

$\mathrm{RB}$ professes allegiance to a number of core values, viz. achievement, entrepreneurship, team spirit, and ownership. ${ }^{6}$ However, none of these is manifestly an ethical value that places particular limitations on profit maximizing behavior. Arguably, achievement is synonymous with performance, entrepreneurship stimulates product innovation, team spirit increases organizational effectiveness, and ownership implies property rights, i.e., patents. Hence, we argue that they are values that support economic performance and they reflect the salient norm that business organizations should employ its resources efficiently to the benefit of its owners. Apart from this, important ethical norms for drug producing companies relate to product safety, since medicine is strongly regulated by governments. Hence, an ethical norm that places limitations on the efficiency of RB's operations is attending to the safety of the users of the product.

Similarly, the values of Tyrili are solidarity, equality, community, tolerance, and honesty. Tyrili's values are explicitly ethical and humanistic 
values and they translate into rehabilitation efforts that exclude a number of approaches from the decision space. Rather, the values reflect a norm that may be formulated to help them aiming to achieve the betterment of one of the most vulnerable groups in society. However, as users of public resources for drug rehabilitation, Tyrili is also subject to a norm that mirrors RB's responsibility to its owners, namely, the effective and efficient use of resources in drug rehabilitation. Such a norm indicates that if other measures are more effective, resources should perhaps be reallocated to other rehabilitation entities.

A significant systemic feature of drug rehabilitation that should be considered in this regard is the boomerang effect, i.e., the continuous return of the same abusers to rehabilitation - partially due to inadequate rehabilitation measures. In Jørgensen and Pedersen's (2010) study, drug abusers reported their experiences of medical treatment as insufficient in helping them become resocialized into society. This implies that one cannot judge the effectiveness of the treatment as a one-shot event; rather one must make evaluations at the broader, systemic level. Hence, one may argue that the medical reductionism inherent in RB's formulation of the drug problem may be an inadequate solution to the drug problem, and that multidimensional problem solving measures are required to increase the success rate of drug rehabilitation. Without question, this requires more resources for each abuser in rehabilitation; however, it may reduce the total amount spent on rehabilitation if the success rate is sufficiently improved. This is an issue that goes beyond the scope of this article. The point to be made here, however, is that the drug problem is one wherein the systemic dimension at least is important to take into account in problem formulation and solving.

Finally, the third element by which we can discuss the organizations' responsibility is by the stakeholder value - $S(A i)$ - of the two approaches, i.e., the component of Zsolnai's (2009) framework that reflects the degree to which the approaches take into account the interests of important stakeholders. In the case description, we outlined the most important stakeholders for the two organizations and the interests of these stakeholders are to varying degrees taken into account in practice.

If we analyze the stakeholder value of the two organizations' approaches based on Zsolnai's (2009) framework, the interests of RB's owners and the public entities allocating resources to Tyrili seem to be managed well, since both organizations are still performing well. The available data does not allow us to draw unambiguous conclusions on the effects on society at large. Also at the level of the individual abuser, it is difficult to point at differences in success between the two approaches. However, we may argue that while there is perhaps no observable difference at the outcome level, the degree of involvement in the well-being of users is different at the process level. Historically, Tyrili managers and employees all lived with drug abusers in the 
drug rehabilitation facility. As such, the activities of the organization can be described as intrinsic solidarity. While the practice of cohabitation has ended, Tyrili's activities are still characterized by being built around and centered on the interests of its users. Also, personal relationships between the employees and the drug abusers are a core element of rehabilitation. Moreover, Tyrili also offers work practice and other activities after rehabilitation has ended. As such, the degree to which the organization assumes responsibility for its main stakeholders extends past its primary objective of rehabilitation. Hence, while RB's social responsibility (as opposed to its environmental responsibility) is mainly manifested in philanthropic activities, Tyrili's social responsibility is intertwined with its organizational activities and in a sense inherent in their operations. At Tyrili, responsibility is not a byproduct - rather, one might argue that it is embedded in the product. $^{7}$

Furthermore, in RB's CSR program, the organization conceives of its responsibility as a byproduct of profitability, in the sense that $\mathrm{RB}$ shares its profits with charity organizations such as Save the Children. Moreover, RB has explicit environmental goals that influence its core business activities by reducing its carbon footprint. This implies that $\mathrm{RB}$ voluntarily includes two other stakeholder groups in the conception of its responsibility, namely vulnerable groups (who are not directly influenced by RB's activities) and nature. It is important to note here that parts of its CSR program have implications for the manner in which they do business, while a large part of the CSR program consists of philanthropic activities that have no impact on the way in which it carries out its actual business operations. Here, a central difference to the approach of Tyrili is also evident.

The final element that should be included in the discussion of stakeholder value relates to how the organizations' activities may displace the interests of others. In the case of $\mathrm{RB}$, we have outlined that a prominent feature of its activities is the active propagation of the medical formulation of the drug problem. Thereby, RB aims to make public and private decision makers, as well as the general public and drug abusers themselves accept the medicalized formulation. With this comprehensive communication strategy, it is effectively displacing other approaches to drug rehabilitation. By successful influence on public policy developments, alliance building with private practitioners, as well as an influence on the perceptions of the general public, it is becoming increasingly difficult for facilities that pursue drug rehabilitation within different paradigms or frameworks. There is of course nothing inherently irresponsible about competition, yet one may question whether RB's practices of coopting medical expertise, thereby influencing public decision making in the drug sector is justifiable. When the implication is that many alternative approaches to rehabilitation are abandoned to the detriment of such organizations, one may question whether RB's practi- 
ces constitute socially irresponsible behavior vis-à-vis the users of nonmedical rehabilitation, for whom the rehabilitation opportunities are strongly decreased.

In a somewhat different way, it can be argued that Tyrili's approach also has a negative influence on stakeholders that may be easy to overlook. Since Tyrili bases its rehabilitation on resource intensive measures, this implies that the total amount of resources available cannot extend to a high number of users. This means that the interests of abusers for whom there is no available capacity (in a hypothetical system where the Tyrili approach was most widespread) would be displaced. As such, there is negative stakeholder value for these individuals in Tyrili's approach.

The threefold discussion above has aimed to explore how the two problem formulations assumed by RB and Tyrili differ along the lines of goal attainment, ethical norms, and stakeholder value. We have indicated how each of the two approaches has its problems in terms of attending to the manifold stakeholders involved. Thereby, we have shed light on the complexities relating to making responsible choice in organizational practice. In the following section, we summarize the key points from the discussion of the case and synthesize them in a table that highlights the theoretical framework's bearing on the discussion.

\section{A synthesis of the case discussion}

In the case discussion, we have illuminated variables that are not easily observable - problem formulations and social responsibility - by drawing inferences from the observable choices and conduct of the case organizations.

First, we defined the issue that encompasses the views of all 'problem solvers' in the sector: finding means to rehabilitate drug abusers, or at least help them to get a better life so that they do not harm themselves or other people. Second, we distinguished the medicalized treatment approach from the alternative social rehabilitation approach to the drug problem. By analyzing the two solution alternatives, we shed light on the underlying problem formulations that shape their decision space. Moreover, we argued that the difference in problem formulations - i.e., in conceptions of what constitutes the desired state and the present state - indicates the goals of the organizations and how they may be attained, but that goal attainment is constrained by ethical norms and the inclusion of stakeholder interests in the conception of the problem. Finally, we have attempted to show how this indicates differences in the ways in which as well as the degree to which the organizations assume social responsibility in their activities. 
In Table 1, we summarize the relationships discussed above. The first column represents the overarching issue in the sector. The second column outlines the case examples used to illustrate the phenomenon, while the third column represents the problem solving measures by each of the two organizations. Thereafter, columns four to six indicate the three elements of responsible decision making subscribed to in each of the two approaches goal attainment, ethical norms (and the values to which they relate), and stakeholder inclusion.

Table 1: A synthesis of the case discussion

\begin{tabular}{|c|c|c|c|c|c|}
\hline $\begin{array}{l}\text { Overarching } \\
\text { issue }\end{array}$ & Cases & $\begin{array}{c}\text { Problem } \\
\text { solving } \\
\text { measures }\end{array}$ & $\begin{array}{c}\text { Problem } \\
\text { formulations } \\
\text { and } \\
\text { organizational } \\
\text { goals }\end{array}$ & $\begin{array}{l}\text { Ethical norms } \\
\text { (and } \\
\text { corresponding } \\
\text { values) }\end{array}$ & $\begin{array}{c}\text { Stakeholder } \\
\text { inclusion and } \\
\text { stakeholder value }\end{array}$ \\
\hline \multirow[t]{2}{*}{$\begin{array}{l}\text { Drug } \\
\text { problem } \\
\text { Finding me- } \\
\text { ans to reha- } \\
\text { bilitate drug } \\
\text { abusers, or } \\
\text { at least help } \\
\text { them to get a } \\
\text { better life so } \\
\text { that they do } \\
\text { not harm } \\
\text { themselves } \\
\text { or other pe- } \\
\text { ople }\end{array}$} & $\begin{array}{l}\text { Medical } \\
\text { treatment } \\
\text { (e.g. } \\
\text { Reckitt } \\
\text { Benckiser) }\end{array}$ & $\begin{array}{l}\text { Produce me- } \\
\text { dicine for tre- } \\
\text { atment of } \\
\text { drug abusers, } \\
\text { facilitate the } \\
\text { use of medici- } \\
\text { ne in treat- } \\
\text { ment (e.g. } \\
\text { deregulation, } \\
\text { educate stake- } \\
\text { holders) }\end{array}$ & $\begin{array}{l}\text { The drug pro- } \\
\text { blem is a medical } \\
\text { problem and we } \\
\text { need to facilitate } \\
\text { medical treat- } \\
\text { ment of drug } \\
\text { abuse in a profi- } \\
\text { table manner }\end{array}$ & $\begin{array}{l}\text { Norms: } \\
\text { (1) Employing } \\
\text { resources effici- } \\
\text { ently to benefit } \\
\text { owners. } \\
\text { (2) Attending to } \\
\text { the safety of the } \\
\text { users of the pro- } \\
\text { duct. } \\
\text { Performance values: } \\
\text { Efficiency, profita- } \\
\text { bility, entrepre- } \\
\text { neurship, } \\
\text { ownership, team } \\
\text { spirit, achievement }\end{array}$ & $\begin{array}{l}\text { Positive stakehol- } \\
\text { der value for inter- } \\
\text { nal stakeholders } \\
\text { (owners), unclear } \\
\text { stakeholder value } \\
\text { for society, negative } \\
\text { stakeholder value } \\
\text { for competitors } \\
\text { (other rehabilitati- } \\
\text { on entities), limited } \\
\text { involvement with } \\
\text { external stakehol- } \\
\text { ders (current users) }\end{array}$ \\
\hline & $\begin{array}{l}\text { Social } \\
\text { rehabilita- } \\
\text { tion } \\
\text { (e.g. Tyrili) }\end{array}$ & $\begin{array}{l}\text { Socially and } \\
\text { existentially } \\
\text { oriented reha- } \\
\text { bilitation me- } \\
\text { asures in the } \\
\text { long term, un- } \\
\text { learning of } \\
\text { (drug) cultur- } \\
\text { al norms and } \\
\text { resocializati- } \\
\text { on }\end{array}$ & $\begin{array}{l}\text { The drug pro- } \\
\text { blem is a com- } \\
\text { plex socio- } \\
\text { cultural and } \\
\text { existential pro- } \\
\text { blem and we } \\
\text { need to address } \\
\text { the various as- } \\
\text { pects of the drug } \\
\text { abuser's conditi- } \\
\text { on while ensur- } \\
\text { ing new clients } \\
\text { from the govern- } \\
\text { ment. }\end{array}$ & $\begin{array}{l}\text { Norms: } \\
\text { (1) Aiming to } \\
\text { achieve the better- } \\
\text { ment of one of the } \\
\text { most vulnerable } \\
\text { groups in society. } \\
\text { (2) Ensuring effec- } \\
\text { tive and efficient } \\
\text { use of resources in } \\
\text { drug rehabilita- } \\
\text { tion. } \\
\text { Humanistic values: } \\
\text { Community, soli- } \\
\text { darity, equality, tol- } \\
\text { erance, honesty }\end{array}$ & $\begin{array}{l}\text { Adequate stakehol- } \\
\text { der value for finan- } \\
\text { cers (government), } \\
\text { unclear stakeholder } \\
\text { value for society, } \\
\text { negative stakehol- } \\
\text { der value for poten- } \\
\text { tial clients for } \\
\text { whom resources } \\
\text { are lacking, exten- } \\
\text { ded involvement } \\
\text { with external stake- } \\
\text { holders (current } \\
\text { users) }\end{array}$ \\
\hline
\end{tabular}


In the case, two approaches - medical treatment and social rehabilitation coexist (column 2). This is evident in the problem solving measures of the organizations (column 2), which reflect the problem formulations (column 4). While the most widespread problem formulation is that the drug problem is a medical one and that medical treatment must be facilitated, the alternative formulation conceives of the problem as a multidimensional one - integrating medical, social, and existential issues. The norms that constrain the activities of the organizations and the values the organizations express (column 5) point toward the outcomes in column 6, namely, the stakeholder value (i.e., that stakeholder interests are attended to in practical decision making) for a number of different stakeholders directly or indirectly influenced by the organizations' activities.

Table 1 illuminates the manner in which the two approaches take into account various important stakeholders in different ways, and include their interests in the formulation and solution of the problem. Moreover, it indicates how organizations' conceptions of norms to some extent are reflected in their expressed values. However, expressed values should be interpreted with caution, since other values altogether may have a more profound bearing on the organizations' activities in practice. The table also indicates that the profit-motive of $\mathrm{RB}$ perhaps translates into a stakeholder interest prioritization that to a lesser extent benefits external stakeholders (i.e. users) at the expense of the organization's goal attainment. However, the table indicates that both organizations produce negative stakeholder value for some external stakeholders. This implies that this is not a black and white case of one organization being responsible and the other being irresponsible. Rather, our discussion of the divergent problem formulations and how they translate into practical decision making indicate how organizations are forced to grapple with the problem of balancing three dimensions of decision making - its own goal attainment, the reverence for relevant norms in its environment and the interests of its stakeholders. This implies that the ways and degrees to which organizations assume responsibility always involve the prioritization of some stakeholders over others. The challenge for these organizations, then, is to determine the most salient stakeholders and the norms to which they must abide, and to adjust their goals and their means accordingly.

\section{Concluding remarks}

In this article, we have aimed to illuminate how organizational problem formulations (1) determine the manner in which the organization attempts to solve the problem and (2) involve the ascription of significance to the interests of a group of stakeholders seen as relevant for the organization. Our 
contribution is based on a problem solving perspective, wherein organizations are viewed as problem solving systems. This implies that they constantly aim to find and implement means to fill the gap between the desired and the present state. We conducted a theory-driven case study to illustrate how organizational problem formulations translate to differences in goal attainment, reverence for norms, and the inclusion of stakeholder interests in practical decision making. Thereby, we have aimed to illuminate how the organizations carry out their social responsibility. We have thereby argued that one important factor in understanding the degree to which and the manner in which organizations assume responsibility for various stakeholders follows from the way in which the organization sees the problem it is faced with.

We have explored key similarities and differences between two cases that are arguably quite different - a large pharmaceutical company and a moderately sized Norwegian drug rehabilitation foundation. However, the purpose of our contribution is not to argue that these organizations should act similarly. Rather, we have juxtaposed how two different organizations operating in the same sector differently conceive of the overarching problem of the sector, and differently attend to key stakeholders within the sector. Furthermore, by exploring the activities of organizations operating at different ends of the spectrum, but with the same overarching issue, we may envision the contours of organizational practices between the two extremes that could be feasible and sustainable for small organizations as well as for large, publically listed corporations. Thereby, we shed light on the realm of possibilities, as well as highlight problems with each of the two problem formulations that coexist in the sector and the problem solving that follows thereof.

The problem we have explored in this study is a complex social issue, and organizational attempts at managing the drug problem have substantial consequences for society at large. Therefore, a critical assessment of the goals that guide those organizations' choices and conduct, the norms that constrain their activities, and the ways in which they assume responsibility for the stakeholders they influence is vital. In this article, we have attempted to contribute to such a responsibility-centered discourse on organizational practices.

\section{Acknowledgements}

We are indebted to Sabina Leitmann for valuable comments and for the feedback from participants at the EBEN Annual Conference 2010 in Trento, Italy, and the CSR conference 2010 in Trondheim, Norway. Also, we are grateful to two anonymous referees for their fruitful feedback. The authors are 
listed alphabetically. This paper is the result of dynamic cooperation, and the authors stand equally responsible for its content.

\section{Literature}

Argyris, C. \& Schön, D. (1974) Theory in Practice: Increasing Professional Effectiveness. San Francisco, CA: Jossey-Bass.

Blau, P.M. \& Scott, W.R. (1962) Formal Organizations: A Comparative Approach. San Francisco, CA: Chandler.

Büyükdamgaci, G. (2003) Process of organizational problem definition: how to evaluate and how to improve. Omega: The International Journal of Management Science, 31, 327-338.

Conrad, P. (2007) The Medicalization of Society on the Transformation of Human Conditions into Treatable Disorders. Baltimore, MD: Johns Hopkins University Press.

Eierman, M. A. \& Philip, G. C. (2003) The Task of Problem Formulation. International Journal of Information Technology \& Decision Making, 2 (3), 353-372.

Eisenhardt, K. M. (1989) Building Theories from Case Study Research. Academy of Management Review, 14 (4), 532-550.

Flyvbjerg, B. (2006) Five Misunderstandings about Case-Study Research. Qualitative Inquiry, 12 (2), 219-245.

Ims, K. J. \& Jakobsen, O. (2006) Cooperation and Competition in the Context of Organic and Mechanic Worldviews: A Theoretical and Case-based Discussion. Journal of Business Ethics, 66, 19-32.

Ims, K. J. \& Zsolnai, L. (2006) Shallow Success and Deep Failure. In Business within Limits: Deep Ecology and Buddhist Economics, eds. L. Zsolnai \& K.J. Ims, pp. 324. Bern: Peter Lang.

Ims, K. J. \& Zsolnai, L. (2009) Holistic Problem Solving. In The Future International Manager: A Vision of the Roles and Duties of Management, eds. L. Zsolnai \& A. Tencati, pp. 116-129. London: Palgrave MacMillan.

Jørgensen, S. (2009) Business as Usual and the Barriers to Sustainable Innovations. Beta: Scandinavian Journal of Business Research, 1, 27-44.

Jørgensen, S. (2010) Baklengs ut av fuglekassa: Komplekse problemer krever komplekse problemformuleringer. Tidsskriftet Norges barnevern, 2, 76-89.

Jørgensen, S. \& L. J. T. Pedersen. (2010) What's the Problem? A Problem-based Approach to the Reform of the Norwegian Drug Rehabilitation Sector. European Journal of Social Work, 13 (3), 339-357.

KRAFT (2008) Gjennomgang av forskningsprosjekter med heroinavhengige. Press release, June 27th 2008, Oslo: Stiftelsen KRAFT.

Lyles, M. A. \& Mitroff, I. I. (1980) Organizational Problem Formulation: An Empirical Study. Administrative Science Quarterly, 25, 102-119.

Mitchell, R. K., Agle, B. R. \& Wood, D. J. (1997) Toward a Theory of Stakeholder Identification and Salience: Defining the Principle of Who and What Really Counts. Academy of Management Review, 22 (4), 853-886.

Mitroff, I. I. (1998) Smart Thinking for Crazy Times: The Art of Solving the Right Problems. San Francisco, CA: Berrett-Koehler Publishers. 
Mitroff, I. I. \& Silvers, A. (2009) Dirty Rotten Strategies: How We Trick Ourselves and Others into Solving the Wrong Problems Precisely. Palo Alto, CA: Stanford University Press.

Pedersen, L. J. T. (2009) See No Evil: Moral Sensitivity in the Formulation of Business Problems. Business Ethics: A European Review, 18 (4), 335-348.

Robin, D. P. \& Reidenbach, R. E. (1987) Social Responsibility, Ethics, and Marketing Strategy: Closing the Gap between Concept and Application. The Journal of Marketing, 51 (1), 44-58.

van Rekom, J., von Riel, C. B. M. \& Wierenga, B. (2006) A Methodology for Assessing Organizational Core Values. Journal of Management Studies, 43 (2), 175201.

Vetlesen, A. J. \& Henriksen, J.-O. (2003) Moralens sjanser i markedets tidsalder: Om kulturelle forutsetninger for moral. Oslo: Gyldendal Akademisk

Vickers, G. (1965) The Art of Judgment: A Study of Policy Making. London: Chapman \& Hall.

Yin, R. K. (2001) Case Study Research: Design and Methods. Thousand Oaks, CA: Sage Publications.

Zsolnai, L. (2009) Responsible Decision Making. New York: Transaction Publishers.

\section{Notes}

1 Vickers' distinction, however, also indicates that values are only part of what plays into and shapes the problem formulation. One's beliefs and interpretation of factual phenomena and events also play a substantial role.

2 See Jørgensen (2010) and Jørgensen and Pedersen (2010) for prior publications based on the broader case study. Parts of the data set were collected while one of the authors was working at Tyrili from 1995 to 1998.

3 It should be noted that there is variation among drug rehabilitation facilities with regard to whether or not they include medical treatment as part of their rehabilitation efforts. Our case organization, Tyrili, offers medically assisted rehabilitation as part of their activities.

4 See www.suboxone.com

5 See www.heretohelpprogram.com

6 See the report Vision and Values at: www.rb.com

7 This point is reminiscent of the famous Nestlé case, which deals with Nestlés marketing of breast milk formula to poor and illiterate consumers in third world countries (see e.g. Robin and Reidenbach, 1987). The Nestlé case deals with the question of whether the company's responsibility ends with the delivery of a safe product, or whether it is reasonable to expect a level of engagement on the part of companies that hinders negative outcomes of the use of the product when vulnerable stakeholders are involved. 